\title{
Comparison between insulin tolerance test, growth hormone (GH)-releasing hormone (GHRH), GHRH plus acipimox and GHRH plus GH-releasing peptide-6 for the diagnosis of adult GH deficiency in normal subjects, obese and hypopituitary patients
}

\author{
Fernando Cordido ${ }^{1,2}$, Paula Alvarez-Castro ${ }^{1}$, Maria Luisa Isidro ${ }^{1}$, Felipe F Casanueva ${ }^{4}$ and Carlos Dieguez ${ }^{3}$ \\ ${ }^{1}$ Department of Endocrinology, Hospital Juan Canalejo, ${ }^{2}$ Department of Medicine University of La Coruña and ${ }^{3}$ Departments of Physiology and \\ ${ }^{4}$ Medicine, University of Santiago, La Coruña and Santiago, Spain \\ (Correspondence should be addressed to F Cordido, Servicio de Endocrinología, Hospital Juan Canalejo, Xubias de Arriba 84, 15006 La Coruña, Spain; \\ Email: fernando_cordido@canalejo.org)
}

\begin{abstract}
Objective: It has been gradually realized that GH may have important physiological functions in adult humans. The biochemical diagnosis of adult GHD is established by provocative testing of GH secretion. The insulin-tolerance test (ITT) is the best validated. The ITT has been challenged because of its low degree of reproducibility and lack of normal range, and is contra-indicated in common clinical situations. Furthermore, in severely obese subjects the response to the ITT frequently overlaps with those found in non-obese adult patients with GHD.

Design: The aim of the present study was to evaluate the diagnostic capability of four different stimuli of GH secretion: ITT, GHRH, GHRH plus acipimox (GHRH+Ac), and GHRH plus GHRP-6 (GHRH+ GHRP-6), in two pathophysiological situations: hypopituitarism and obesity, and normal subjects. Methods: Eight adults with hypopituitarism (four female, four male) aged 41-62 years (48.8 \pm 1.4 years), ten obese normal patients (five female, five male) aged 38-62 years (48.1 2.5 years), with a body mass index of $34.2 \pm 1.2 \mathrm{~kg} / \mathrm{m}^{2}$, and ten normal subjects (five female, five male) aged 33-62 years $(48.1 \pm 2.8$ years) were studied. Four tests were performed on each patient or normal subject: An ITT $(0.1 \mathrm{U} / \mathrm{kg}, 0.15 \mathrm{U} / \mathrm{kg}$ for obese, i.v., $0 \mathrm{~min})$, GHRH $(100 \mu \mathrm{g}$, i.v., $0 \mathrm{~min})$, GHRH $(100 \mu \mathrm{g}$, i.v., $0 \mathrm{~min})$ preceded by acipimox $(250 \mathrm{mg}$, orally, at $-270 \mathrm{~min}$ and $-60 \mathrm{~min})$ (GHRH+Ac); and GHRH (100 ug, i.v., 0 min) plus GHRP-6 (100 $\mu$ g, i.v., 0 min) (GHRH + GHRP-6). Serum GH was measured by radioimmunoassay. Statistical analyses were performed by Wilcoxon rank sum and by Mann-Whitney tests.

Results: After the ITT the mean peak GH secretion was $1.5 \pm 0.3 \mu \mathrm{g} / \mathrm{l}$ for hypopituitary, $10.1 \pm 1.7 \mu \mathrm{g} / \mathrm{l}$ $(P<0.05$ vs hypopituitary) for obese and $17.8 \pm 2.0 \mu \mathrm{g} / \mathrm{l}(P<0.05$ vs hypopituitary) for normal. GHRH-induced GH secretion was $2 \pm 0.7 \mu \mathrm{g} / \mathrm{l}$ for hypopituitary, 3.9 $\pm 1.2 \mu \mathrm{g} / \mathrm{l}(P=\mathrm{NS}$ vs hypopituitary) for obese and $22.2 \pm 3.8 \mu \mathrm{g} / \mathrm{l}(P<0.05$ vs hypopituitary) for normal. After GHRH+Ac, mean peak GH secretion was $3.3 \pm 1.4 \mu \mathrm{g} / \mathrm{l}$ for hypopituitary, $14.2 \pm 2.7 \mu \mathrm{g} / \mathrm{l}(P<0.05$ vs hypopituitary $)$ for obese and $35.1 \pm 5.2 \mu \mathrm{g} / \mathrm{l}(P<0.05$ vs hypopituitary) for normal. GHRH + GHRP-6 induced mean peak GH secretion of $4.1 \pm 0.9 \mu \mathrm{g} / \mathrm{l}$ for hypopituitary, $38.5 \pm 6.5 \mu \mathrm{g} / \mathrm{l}(P<0.05$ vs hypopituitary) for obese and $68.1 \pm 5.5 \mu \mathrm{g} / \mathrm{l}(P<0.05$ vs hypopituitary) for normal subjects. Individually considered, after ITT, GHRH or GHRH+Ac, the maximal response in hypopituitary patients was lower than the minimal response in normal but higher than the minimal response in obese subjects. In contrast, after GHRH+GHRP-6 the maximal response in hypopituitary patients was lower than the minimal response in normal and obese subjects.

Conclusions: This study suggests that, in this group of patients, although both acipimox and GHRP-6 partially reverse the functional hyposomamotropism of obesity after GHRH, but are unable to reverse the organic hyposomatotropism of hypopituitarism, the combined test GHRH+GHRP-6 most accurately distinguishes both situations, without the side effects of ITT.
\end{abstract}

European Journal of Endocrinology 149 117-122

\section{Introduction}

It has been gradually realized that $\mathrm{GH}$ may have important physiological functions in adult humans. Several studies have shown that $\mathrm{GH}$ deficiency
(GHD) in adults (GHDA) is associated with abnormalities in body composition, metabolic derangements and sub-optimal physical performances, and that these impairments improve with GH replacement therapy $(1-3)$. 
On the basis of overwhelming evidence that adults with GHD have impaired health that improves with GH replacement (4), many countries have already approved such treatment for these patients. The features of GHDA are recognisable but not distinctive, so clinical suspicion must be confirmed by biochemical tests. The biochemical diagnosis of GHDA is established by provocative testing of GH secretion (5). The insulintolerance test (ITT) is the best validated and is recommended by the Growth Hormone Research Society as the test of choice (6), an abnormal response being ITT-mediated GH peak below $5 \mu \mathrm{g} / \mathrm{l}$. Severe GHD is defined as a GH response lower than the arbitrary cut-off value of $3 \mu \mathrm{g} / \mathrm{l}(6)$. The ITT has been challenged because of its low degree of reproducibility and lack of normal range (7), and is contra-indicated in common clinical situations in adult patients with suspected GH. ITT is contra-indicated in patients with ischemic heart disease, seizure disorders and aging (8). Furthermore, in severely obese subjects the response to the ITT frequently overlaps with those found in non-obese adult patients with GHD. Therefore, most clinicians would welcome a more convenient diagnostic test associated with less discomfort for adult patients.

Some recent studies have evaluated alternative tests for the diagnosis of GHDA $(9-16)$ and have found that those tests could be used for the diagnosis of that situation, but they did not specifically consider what is probably the most important confounding factor, that is obesity after different stimuli of GH secretion.

The aim of the present study was to evaluate the diagnostic capability of four different stimuli of $\mathrm{GH}$ secretion: ITT, GHRH, GHRH+Ac, and GHRH+ GHRP-6, in two pathophysiological situations: hypopituitarism and obesity, and normal subjects.

\section{Subjects and methods}

Eight adults with hypopituitarism and adult onset GHD (four female, four male) aged 41-62 years $(48.8 \pm 1.4$ years), ten obese normal patients (five female, five male) aged 38-62 years $(48.1 \pm 2.5$ years), with a body mass index (BMI) of $34.2 \pm 1.2 \mathrm{~kg} / \mathrm{m}^{2}$, and ten normal subjects (five female, five male) aged 33-62 years $(48.1 \pm 2.8$ years) were studied.

The diagnosis of hypopituitarism was established by a history of structural pituitary or hypothalamic lesion treated with surgery and/or radiotherapy necessitating end-organ hormonal substitution for any combination of a thyroid, adrenal or gonadal failure. All hypopituitary patients showed an impaired response to an ITT $(0.1 \mathrm{U} / \mathrm{kg}$, i.v. $)$, with a peak GH secretion of less than $3 \mu \mathrm{g} / \mathrm{l}$. Where indicated, patients were receiving physiologic replacement doses of L-thyroxin and/or glucocorticoids and/or gonadal steroids. The etiologic diagnosis in the hypopituitary patients was: four non-functioning pituitary adenomas, one surgery-treated pituitary macroprolactinoma, one Sheehans' syndrome, one empty sella turcica, and one idiopathic hypopituitarism.

Obese patients had a BMI greater than $30 \mathrm{~kg} / \mathrm{m}^{2}$ (normal range $20-25 \mathrm{~kg} / \mathrm{m}^{2}$ ). Normal subjects had a BMI between $20-25 \mathrm{~kg} / \mathrm{m}^{2}$. None of the obese or normal subjects had diabetes mellitus or other medical problems, nor were they taking any drugs. All subjects gave informed consent and approval for this study was obtained from the hospital committee. The subjects had been eating a weight-maintaining diet for several weeks prior to the study.

Four tests were carried out for each patient or normal subject, each one separated by at least 1 week. The tests were started at $0900 \mathrm{~h}$ after an overnight fast, with the subjects recumbent. The tests carried out were: ITT $(0.1 \mathrm{U} / \mathrm{kg}, 0.15 \mathrm{U} / \mathrm{kg}$ for obese patients, i.v., $0 \mathrm{~min})$; GHRH $(100 \mu \mathrm{g}$, i.v., $0 \mathrm{~min})$; GHRH $(100 \mu \mathrm{g}$, i.v., $0 \mathrm{~min})$ preceded by acipimox $(250 \mathrm{mg}$, orally, at $-270 \mathrm{~min}$ and $-60 \mathrm{~min})(\mathrm{GHRH}+\mathrm{Ac})$; and GHRH

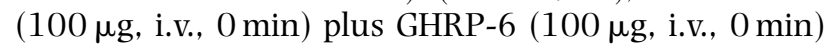
(GHRH+GHRP-6). Blood samples were obtained every $15 \mathrm{~min}$ over the following $90 \mathrm{~min}$ of testing through an indwelling catheter placed in a forearm vein and kept patent by a slow infusion of saline.

Serum GH was measured by radioimmunoassay (Nichols Institute, San Juan Capistrano, CA, USA) with a sensitivity of $0.04 \mathrm{ug} / \mathrm{l}$ and with intra-assay coefficients of variation of $4.2,2.9$ and $2.8 \%$ for low, medium and high plasma GH levels, respectively. Free fatty acid (FFA) levels were determined by an enzymatic colorimetric method (NEFA-HA, Wako, Zaragoza, Spain). All samples from a given subject were analyzed in the same assay run. Hormone levels are presented as absolute values or as the mean GH peak.

Statistical analyses were performed by Wilcoxon rank sum between related groups and by Mann-Whitney tests between different groups. Results are expressed as mean \pm S.E.M. and $P<0.05$ was considered significant.

\section{Results}

The response of the groups of patients and normal subjects are presented in Tables 1-3.

After the ITT the mean peak GH secretion was $1.5 \pm 0.3 \mu \mathrm{g} / \mathrm{l}$ for hypopituitary patients, 10.1 \pm $1.7 \mu \mathrm{g} / \mathrm{l}(P<0.05$ vs hypopituitary) for obese patients, and $17.8 \pm 2.0 \mu \mathrm{g} / \mathrm{l}(P<0.05$ vs hypopituitary $)$ for normal subjects. Mean peak GHRH-induced GH secretion was $2 \pm 0.7 \mu \mathrm{g} / \mathrm{l}$ for hypopituitary patients, $3.9 \pm 1.2 \mu \mathrm{g} / \mathrm{l} \quad(P=\mathrm{NS}$ vs hypopituitary) for obese patients, and $22.2 \pm 3.8 \mu \mathrm{g} / \mathrm{l}(P<0.05$ vs hypopituitary) for normal subjects. After GHRH + Ac the mean peak GH secretion was $3.3 \pm 1.4 \mu \mathrm{g} / \mathrm{l}$ for hypopituitary patients, $14.2 \pm 2.7 \mu \mathrm{g} / \mathrm{l}(P<0.05$ vs hypopituitary $)$ for obese patients, and $35.1 \pm 5.2 \mu \mathrm{g} / \mathrm{l}(P<0.05$ vs hypopituitary) for normal subjects. Mean peak GHRH 
Table 1 Peak $\mathrm{GH}(\mu \mathrm{g} / \mathrm{l})$ secretion in hypopituitary patients after different stimuli of GH secretion. Patients' ages (in years) and gender are given in brackets.

\begin{tabular}{lcccc}
\hline Patient & ITT & GHRH & GHRH+ Ac & GHRH+ GHRP-6 \\
\hline $1(53, \mathrm{w})$ & 1 & 3.8 & 5.8 & 5.6 \\
$2(54, \mathrm{w})$ & 0.5 & 4.0 & 4.1 & 2.9 \\
$3(62, \mathrm{~m})$ & 2.5 & 2.9 & 7.1 & 3.0 \\
$4(47, \mathrm{w})$ & 1 & 0.2 & 0.1 & 0.1 \\
$5(29, \mathrm{~m})$ & 2 & 1 & 2.7 & 7.5 \\
$6(61, \mathrm{~m})$ & 1 & 0.2 & 0.3 & 5.2 \\
$7(43, \mathrm{w})$ & 1.9 & 0.7 & 2.3 & 6.7 \\
$8(41, \mathrm{~m})$ & 1.8 & 2.7 & 4.3 & 1.9 \\
X \pm SEM: & $1.5 \pm 0.3$ & $2.0 \pm 0.7$ & $3.3 \pm 1.4$ & $4.1 \pm 0.9$ \\
\hline
\end{tabular}

$w$, female, $m$, male.

Table 2 Peak GH ( $\mu \mathrm{g} / \mathrm{l})$ secretion in obese subjects after different stimuli of GH secretion. Subjects' ages (in years) and gender are given in brackets.

\begin{tabular}{lrrcc}
\hline Subject & ITT & GHRH & GHRH+ Ac & GHRH+GHRP-6 \\
\hline $1(53, w)$ & 10.6 & 0.7 & 7.4 & 15.3 \\
$2(42, w)$ & 14.3 & 2.4 & 15.8 & 14.7 \\
$3(49, w)$ & 16.6 & 1.5 & 6.2 & 55.2 \\
$4(41, \mathrm{~m})$ & 11.1 & 11.5 & 36 & 41 \\
$5(43, \mathrm{w})$ & 16.6 & 2.3 & 17 & 86 \\
$6(38, \mathrm{~m})$ & 12.4 & 9.9 & 14.9 & 41 \\
$7(62, \mathrm{~m})$ & 3.8 & 2.9 & 13.3 & 35.3 \\
$8(54, \mathrm{w})$ & 10.4 & 3.3 & 11.5 & 33.4 \\
$9(44, \mathrm{~m})$ & 3.1 & 2.8 & 8.2 & 39.2 \\
$10(55, \mathrm{~m})$ & 2.3 & 1.9 & 11.6 & 23.5 \\
X \pm SEM: & $10.1 \pm 1.7$ & $3.9 \pm 1.2$ & $14.2 \pm 2.7$ & $38.5 \pm 6.5$ \\
\hline
\end{tabular}

Table 3 Peak $\mathrm{GH}(\mu \mathrm{g} / \mathrm{l})$ secretion in normal subjects after different stimuli of GH secretion. Subjects' ages (in years) and gender are given in brackets.

\begin{tabular}{lcccc}
\hline Subject & ITT & GHRH & GHRH+AC & GHRH+GHRP-6 \\
\hline $1(33, \mathrm{~m})$ & 18.7 & 41.8 & 23 & 53.3 \\
$2(47, \mathrm{~m})$ & 15.0 & 19.6 & 35.8 & 86.1 \\
$3(41, \mathrm{w})$ & 25.3 & 19.6 & 48.8 & 76.7 \\
$4(43, \mathrm{w})$ & 26 & 25.5 & 38.7 & 63.2 \\
$5(52, \mathrm{w})$ & 28.5 & 45.1 & 13.7 & 52.7 \\
$6(44, \mathrm{w})$ & 15.5 & 10.8 & 68.4 & 73.4 \\
$7(62, \mathrm{~m})$ & 11.2 & 19.7 & 44.2 & 31.9 \\
$8(51, \mathrm{~m})$ & 10.3 & 18.5 & 35.3 & 78.8 \\
$9(49, \mathrm{w})$ & 14.1 & 11.5 & 30.7 & 80.7 \\
$10(59, \mathrm{~m})$ & 13.3 & 9.9 & 12.8 & 84.3 \\
X \pm SEM & $17.8 \pm 2.0$ & $22.2 \pm 3.8$ & $35.1 \pm 5.2$ & $68.1 \pm 5.5$ \\
\hline
\end{tabular}

plus GHRP-6 induced GH secretion was $4.1 \pm 0.9 \mu \mathrm{g} / \mathrm{l}$ for hypopituitary patients, 38.5 $\pm 6.5 \mu \mathrm{g} / \mathrm{l}(P<0.05 \mathrm{vs}$ hypopituitary) for obese patients, and $68.1 \pm 5.5 \mu \mathrm{g} / \mathrm{l}$ $(P<0.05$ vs hypopituitary) for normal subjects (Fig. 1).

The administration of acipimox induced a FFA reduction during the entire test that was similar for hypopituitary patients, obese patients and normal subjects.

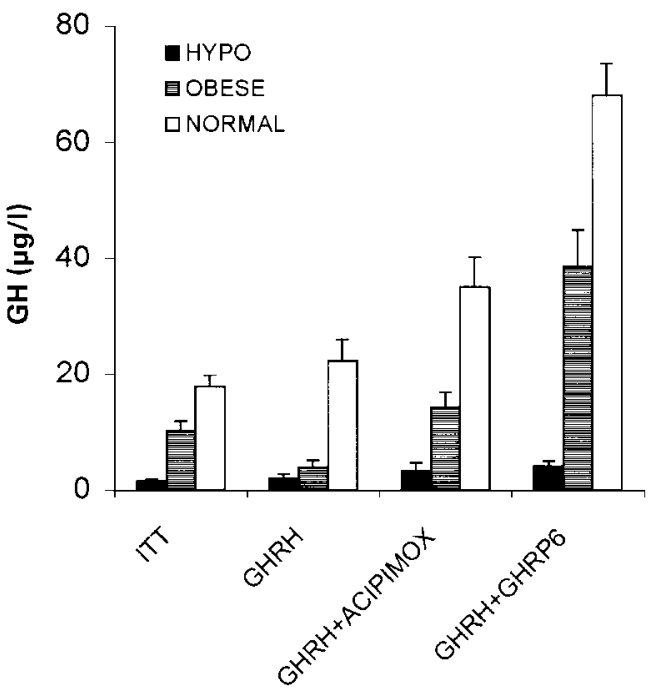

Figure 1 Mean \pm S.E.M. peak serum GH $(\mu \mathrm{g} / \mathrm{l})$ levels in normal subjects, obese and hypopituitary patients after the administration of ITT, GHRH, GHRH+Ac or GHRH+GHRP-6. HYPO, hypopituitary patients.

The differential between normal subjects and hypopituitary patients for GHRH+GHRP-6 $(64 \mu \mathrm{g} / \mathrm{l})$ was higher $(P<0.05)$ than for the ITT $(16.3 \mu \mathrm{g} / \mathrm{l})$, GHRH $(20.2 \mu \mathrm{g} / \mathrm{l})$, and GHRP+Ac $(31.8 \mu \mathrm{g} / \mathrm{l})$. The differential between obese and hypopituitary patients for GHRH+ GHRP-6 was $(34.4 \mu \mathrm{g} / \mathrm{l})$ higher $(P<0.05)$ than for the ITT $(8.6 \mu \mathrm{g} / \mathrm{l})$, GHRH $(1.9 \mu \mathrm{g} / \mathrm{l})$ and GHRP + Ac (10.9 $\mu \mathrm{g} / \mathrm{l})$.

Individually considered, after ITT the maximal response in hypopituitary subjects was $2.5 \mu \mathrm{g} / \mathrm{l}$. This response was lower than the minimal response in normal subjects of $10.3 \mathrm{ug} / \mathrm{l}$ but higher than the minimal response in obese subjects of $2.3 \mu \mathrm{g} / \mathrm{l}$. After GHRH stimuli the maximal response in hypopituitary subjects was $4 \mu \mathrm{g} / \mathrm{l}$. This response was lower than the minimal response in normal subjects of $9.9 \mu \mathrm{g} / \mathrm{l}$ but higher than the minimal response in obese subjects of $0.7 \mu \mathrm{g} / \mathrm{l}$. After GHRH+Ac stimuli the maximal response in hypopituitary subjects was $7.1 \mu \mathrm{g} / \mathrm{l}$. This response was lower than the minimal response in normal subjects of $12.8 \mu \mathrm{g} / \mathrm{l}$ but higher than the minimal response in obese subjects of $6.2 \mu \mathrm{g} / \mathrm{l}$. In contrast, after GHRH+ GHRP-6 stimuli the maximal response in hypopituitary subjects was $7.5 \mu \mathrm{g} / \mathrm{l}$. This response was lower than the minimal response in normal subjects of $31.9 \mu \mathrm{g} / \mathrm{l}$ and also lower than the minimal response in obese subjects of $14.7 \mu \mathrm{g} / \mathrm{l}$.

No significant side effects were observed with the different tests. After ITT clinical symptoms of hypoglycemia were present in all patients. One hypopituitary patient, one obese patient and one normal subject experienced a mild transient facial flushing after the first dose of acipimox. No side effects were reported in the other tests and no test had to be stopped. 


\section{Discussion}

This study demonstrates that when studied in a small group of hypopituitary patients with adult onset GHD, obese patients and normal subjects, GHRH+GHRP-6 is the most reliable test for the diagnosis of GHDA when compared with ITT, GHRH and GHRH+Ac.

The approach to the diagnosis of GHDA requires a high index of suspicion. It should include adults who in childhood received $\mathrm{GH}$ for pituitary dwarfism and adults with known or suspected pituitary disease $(8,17)$. Some recent studies have suggested that the presence of three or more pituitary hormone deficiencies or serum IGF-I concentrations with a certain specific assay could be used for the diagnosis of GHD (18). Due to its pronounced intra-individual fluctuations, determination of basal plasma concentrations of $\mathrm{GH}$ is of no value for the diagnosis of GHD, and considerable overlap with healthy control groups precludes determination of IGF-I and IGFBP-3 (19, 20), analysis of $\mathrm{GH}$ pulses (21), and/or GH determination in pooled serum samples or in urine (22). Therefore, most investigators agree that stimulation tests are indispensable to define GHDA $(19-21,23)$. The insulin hypoglycemia test is the diagnostic test of choice for GHDA (5). The criteria for profound GHD is met if the patient is symptomatic of hypoglycemia, the blood glucose is below $2.2 \mathrm{mmol} / \mathrm{l}$, and the peak $\mathrm{GH}$ response is less than $3 \mu \mathrm{g} / \mathrm{l}(8)$. It is in these patients, who for the most part had a peak GH response to ITT of less than $3 \mu \mathrm{g} / \mathrm{l}$, that beneficial responses with $\mathrm{GH}$ treatment have been observed $(2,3,24)$. The ITT may not be the best tool for the diagnosis of GHDA. The reproducibility of the ITT has been questioned in normal adults (7). A reference for the ITT will be difficult to establish, and it may be impossible to evaluate the possible influences of sex, age, body composition, and cortisol levels in ITT-stimulated GH levels, as patients find the ITT unpleasant. Furthermore the ITT is potentially hazardous (25).

Some recent studies have evaluated alternative tests for the diagnosis of GHDA $(9-16,26)$ and have found that those tests could be used for the diagnosis of that situation. The GHRH+GHRP- 6 test has been considered a convenient, safe and reliable test for GHDA and is not confounded by clinical factors, which are known to alter GH secretory patterns. In the study by Popovic et al. (9) an evoked GH concentration of $>15 \mu \mathrm{g} / \mathrm{l}$ accurately distinguished between healthy and GH-deficient adults. But there have not been studies comparing different alternative tests for the diagnosis of GHDA. As suggested by Ho (27), the problem of false-negative results is probably not completely solved. Since GHRH and GHRP-6 act directly on the pituitary, it is possible that their administration restored $\mathrm{GH}$ secretion in patients who had a deficiency of these secretagogs because of hypothalamic disease. This possibility is supported by the finding that some patients with idiopathic GHD, identified by a poor response to ITT, show an exuberant response to combined administration of GHRH and a GHRP analog $(28,29)$. Thus the combined test may best be used to assess patients with pituitary disease. Among GHdeficient patients who may have substantial hypothalamic dysfunction, the ITT remains the preferred test since it stimulates GH secretion indirectly through the hypothalamus (27). In contrast, it has been suggested that $\mathrm{GH}$ secretagogs may have a role in the diagnosis of GHD even in treated acromegaly (12).

Obesity-related limitation of GH secretion in response to all stimuli has attracted considerable study. Although enhancement of GH clearance is a contributing factor (30), the main altered mechanism in obesity is the impaired GH secretion, either stimulated or spontaneous $(31,32)$. We and others (31) have found that in obese subjects GH secretion is greatly impaired, and could be confused with the syndrome of GHDA. Obesity is probably the most important confounding factor for the diagnosis of GHDA. We have previously studied the response of obese normal subjects and compared that with the response of hypopituitary patients. The $\mathrm{GH}$ response of obese normal patients and obese adults with hypopituitarism was similar after GHRH alone. In contrast, the $\mathrm{GH}$ response after GHRH+Ac was markedly decreased in obese adults with hypopituitarism compared with obese normal patients. We conclude that GH secretion after GHRH+Ac administration is reduced in obese adult patients with hypopituitarism when compared with obese normal patients, and that testing with GHRH+Ac is safe and free from side effects and could be used for the diagnosis of GHDA (33, 34). Recent studies have confirmed this data in patients that have undergone pituitary surgery (26).

After GHRH+GHRP-6 the maximal response in hypopituitary subjects was lower than the minimal response in normal subjects and lower than the minimal response in obese subjects. In contrast, after ITT, GHRH or GHRH + Ac, the maximal response in hypopituitary was lower than the minimal response in normal subjects, but higher than the minimal response in obese subjects. The GHRH+GHRP- 6 test best distinguishes the decreased GH secretion of obesity from GHDA. In agreement with these data we have also found that the differential between normal subjects or obese patients and hypopituitary patients for GHRH+ GHRP-6 was higher than for ITT, GHRH or GHRP+Ac. The main limitation of our study is the small number of patients studied and we think that further studies are still needed, including younger subjects with GHD, to confirm our data. If we want better criteria for GHD in the near future it would probably need to be based on outcomes after GH therapy (23).

In conclusion, this study suggests that in this group of patients, although both acipimox and GHRP-6 partially reverse the functional hyposomamotropism 
of obesity after GHRH, but are unable to reverse the organic hyposomatotropism of hypopituitarism, the combined GHRH+GHRP-6 test most accurately distinguishes both situations, without the side effects of ITT.

\section{Acknowledgements}

This work was supported by a grant from Xunta de Galicia (PGIDTOOPXIO00PR) and FIS of the Instituto de Salud Carlos III (PIO21479 and G03/028).

\section{References}

1 De Boer H, Blok G-J \& van der Veen E. Clinical aspects of growth hormone deficiency in adults. Endocrine Reviews 199516 63-86.

2 Salomon F, Cuneo RC, Hesp R \& Sönksen PH. The effects of treatment with recombinant human growth hormone on body composition and metabolism in adults with growth hormone deficiency. The New England Journal of Medicine 1989321 1797-1803.

3 Jorgensen JOL, Pedersen SA, Thuesen L, Jorgensen J, Ingemann-Hansen T, Skakkebaek EN \& Christiansen JS. Beneficial effects of growth hormone treatment in GH-deficient adults. Lancet 1989 i $1221-1225$.

4 Carroll PV, Christ ER, Bengtsson BA, Carlsson L, Christiansen JS, Clemmons D et al. Growth hormone deficiency in adulthood and the effects of growth hormone replacement: a review. Journal of Clinical Endocrinology and Metabolism $1998 \mathbf{8 3}$ 382-395.

5 Hoffman DM, O'Sullivan AJ, Baxter RC \& Ho KKY. Diagnosis of growth hormone deficiency in adults. Lancet $1994 \mathbf{3 4 3}$ $1064-1068$.

6 Growth Hormone Research Society (GRS). Consensus guidelines for the diagnosis and treatment of adults with growth hormone deficiency. Journal of Clinical Endocrinology and Metabolism 1998 83 379-381.

7 Hoeck HC, Vestergoard P, Jakobson PE \& Laurberg P. Test of growth hormone secretion in adults: poor reproducibility of the insulin tolerance test. European Journal of Endocrinology 1995 133 305-312.

8 Thorner MO, Bengtsson BA, Ho KKY, Albertsson-Wikland K, Christiansen JS, Faglia G et al. Diagnosis of growth hormone deficiency in adults. Journal of Clinical Endocrinology and Metabolism $1995 \mathbf{8 0} 3097-3098$.

9 Popovic V, Leal A, Micic D, Koppeschaar HPF, Torres E, Paramo C et al. GH-releasing hormone and GH-releasing peptide- 6 for diagnostic testing in GH-deficient adults. Lancet $2000 \mathbf{3 5 6}$ 1137-1142.

10 Aimaretti G, Baffoni C, Bellone S, Di Vito L, Corneli G, Arvat E et al. Retesting young adults with childhood-onset growth hormone (GH) deficiency with GH-releasing hormone-plus arginine test. Journal of Clinical Endocrinology and Metabolism $2000 \mathbf{8 5}$ 3693-3699.

11 Schutz F, Wuster C, Heilman P, Ziegler R \& Hadji P. No advantage of the new combined octreotide-GHRH test over established GH-stimulation tests in the diagnosis of growth hormone deficiency (GHD) in adults. Clinical Endocrinology $2000 \mathbf{5 3}$ 667-674.

12 Murray RD, Peacey SR, Rahim A, Toogood AA, Thorner MO \& Shalet SM. The diagnosis of growth hormone deficiency (GHD) in successfully treated acromegalic patients. Clinical Endocrinology $20015437-44$.
13 Rahim A, Toogood AA \& Shalet SM. The assessment of growth hormone status in normal young males using a variety of provocative agants. Clinical Endocrinology 199645 557-562.

14 Maghnie M, Cavigioli F, Tinelli C, Autelli M, Arico M, Aimaretti G \& Ghigo E. GHRH plus arginine in the diagnosis of acquired $\mathrm{GH}$ deficiency of childhood-onset. Journal of Clinical Endocrinology and Metabolism 200287 2740-2744.

15 Biller BM, Samuels MH, Zagar A, Cook DM, Arafah BM, Bonert V, Stavrou S, Kleinberg DL, Chipman JJ \& Hartman ML. Sensitivity and especificity of six tests for the diagnosis of adult GH deficiency. Journal of Clinical Endocrinology and Metabolism $2002 \mathbf{8 7}$ 2067-2079.

16 Petersenn S, Jung R \& Beil FU. Diagnosis of GH deficiency in adults by testing with GHRP-6 alone or in combination with GHRH: comparison with the insulin tolerance test. European Journal of Endocrinology $2002146667-672$.

17 Toogood AA, Colin G, Beardwell CG \& Shalet SM. The severity of growth hormone deficiency in adults with pituitary disease is related to the degree of hypopituitarism. Clinical Endocrinology $199441511-516$.

18 Hartman ML, Crowe BJ, Biller BM, Ho KY, Clemmons DR \& Chipman JJ. Which patients do not require a $\mathrm{GH}$ stimulation test for the diagnosis of adult GH deficiency. Journal of Clinical Endocrinology and Metabolism 200287 477-485.

19 Borges JLC, Gelato MC, Furlanetto R, Rogol AD, Evans WS, Vance ML et al. Effects of human pancreatic tumor growth hormone releasing factor on growth hormone and somatomedin $\mathrm{C}$ levels in patients with idiopathic growth hormone deficiency. Lancet 1983 ii $119-123$.

20 Ho KKY \& Hoffman DM. Defining growth hormone deficiency in adults. Metabolism 199544 (Suppl 4) 91-96.

21 Baum HBA, Biller BMK, Katznelson L, Oppenheim DS, Clemmons DR, Cannistraro KB et al. Assessment of GH secretion in men with adult-onset GH deficiency compared with that in normal men. A clinical research center study. Journal of Clinical Endocrinology and Metabolism 199681 84-92.

22 Moreira Andres MN, Canizo FJ \& Hawkins F. Is there a place for urinary growth hormone measurement? Acta Endocrinologica 1993128 197-201.

23 Molitch ME. Diagnosis of GH deficiency-How good do the criteria need to be? Journal of Clinical Endocrinology and Metabolism 2002 $87473-476$.

24 Bengtsson B-A, Edén S, Lönn L, Kvist H, Stokland A, Lindstedt G et al. Treatment of adults with $\mathrm{GH}$ deficiency with recombinant human GH. Journal of Clinical Endocrinology and Metabolism $199376309-317$.

25 Shah A, Stanhope R \& Matthew D. 1992 Hazards of pharmacological tests of growth hormone secretion in childhood. British Medical Journal $1992 \mathbf{3 0 4} 173-174$.

26 van Dam PS, Dieguez C, Cordido F, de Vries WR, Veldhuizen B, Casanueva FF \& Koppeschaar HPF. Diagnosis of growth hormone deficiency after pituitary surgery: The acipimox/GHRH test. Clinical Endocrinology $2003 \mathbf{5 8} 156-162$.

27 Ho KKY. Diagnosis of adult GH deficiency. Lancet $2000 \mathbf{3 5 6}$ 1125-1126.

28 Leal-Cerro A, Garcia E, Astorga R, Casanueva FF \& Dieguez C. Growth hormone $(\mathrm{GH})$ responses to the combined administration of GH-releasing peptide 6 in adults with GH deficiency. European Journal of Endocrinology 1995132 712-715.

29 Mahajan T \& Lightman SL. A simple test for growth hormone deficiency in adults. Journal of Clinical Endocrinology and Metabolism 200085 1473-1476.

30 Veldhuis JD, Iranmanesh A, Ho KK, Waters MJ, Johnson ML \& Lizarralde G. Dual defects in pulsatile GH secretion and clearance subserve the hypososmatotropism of obesity in man. Journal of Clinical Endocrinology and Metabolism $1991 \quad \mathbf{7 2}$ 492-495.

31 Dieguez C \& Casanueva FF. Influence of metabolic substrates and obesity on growth hormone secretion. Trends in Endocrinology and Metabolism $1995655-59$. 
32 Cordido F, Dieguez C \& Casanueva FF. Effect of central cholinergic neurotransmission enhancement by pyridostigmine on the growth hormone secretion elicited by clonidine, arginine or hypoglycemia in normal and obese subjects. Journal of Clinical Endocrinology and Metabolism 199070 1361-1370.

33 Cordido F, Fernandez T, Martinez T, Peinó R, Dieguez C \& Casanueva F. Effect of acute pharmacological reduction of plasma free fatty acids on GHRH-induced GH secretion in obese adults with and without hypopituitarism. Journal of Clinical Endocrinology and Metabolism 199883 4350-4354.
34 Cordido F, Peino R, Peñalva A, Alvarez CV, Casanueva FF \& Dieguez C. Impaired growth hormone secretion in obese subjects is partially reversed by acipimox-mediated plasma free fatty acid depression. Journal of Clinical Endocrinology and Metabolism 1996 $81914-918$.

Received 3 April 2003

Accepted 21 May 2003 